\title{
CONTEMPORARY ESTHETIC PERIODONTICS
}

\author{
Diana Bronstein ${ }^{1 a^{*}}$, Kevin Suzuki ${ }^{2 b}$, Mehdi Garashi ${ }^{1 c}$, Jon B Suzuki ${ }^{13,4,5,6,7, d}$ \\ 'Department of Periodontology, College of Dental Medicine, Health Profession Division, Nova Southeastern University, Fort Lauderdale, FL, USA \\ ${ }^{2}$ Department of Periodontology and Oral Implantology, School of Dentistry, Temple University, Philadelphia, PA, USA \\ ${ }^{3}$ Microbiology and Immunology, School of Medicine, Temple University, Philadelphia, PA, USA \\ ${ }^{4}$ Periodontology and Oral Implantology, School of Dentistry, Temple University, Philadelphia, PA, USA \\ ${ }^{5}$ National Naval Medical Command, U. S. Navy, Bethesda, MD, USA \\ ${ }^{6}$ Department of Periodontology, School of Dentistry, University of Maryland, Baltimore, MD, USA \\ ${ }^{7}$ Maimonides University, Buenos Aires, Argentina
}

aDS, MS, MS, Associate Professor, Associate Director of Predoctoral Periodontology

${ }^{b} D M D, M S$, Clinical Assistant Professor

'DDS, Postgraduate Resident

${ }^{d} D D S$, PhD, MBA, Clinical Professor

Received: August 16, 2016

Revised: August 23, 2016

Accepted: September 07, 2016

Cite this article:

Published: September 08, 2016

Bronstein D, Suzuki K, Garashi M, Suzuki JB. Contemporary Esthetic Periodontics. Stoma Edu J. 2016;3(3-4):212-222.

DOI: https://doi.org/10.25241/stomaeduj.2016.3(3-4).art.12

Aim: In contemporary dentistry, disease prevention and regeneration have dictated the paradigm shift from the practitioner's reactive approach to disease occurrence in his increasingly educated and demanding patient population to an innovative and proactive patient treatment. This clinical paper with case reports will address these aspects of muco-gingival surgery around teeth and implants.

Summary: Successful periodontal disease control and elimination by skilled dental professionals may leave patients with an esthetic or sensitivity concern. The historical "longer teeth, or no longer teeth" and its sequela require targeted intervention from today's dental team to prevent lesion progression and improve patient satisfaction.

After surgical technique and patient compliance with oral hygiene and wound care instructions, the patient's physiology, immunology and molecular biology, is responsible for the clinical outcome of the procedure.

Key Learning Points: In cases with lack of keratinized attached gingiva, the results of the present case reports on teeth and implants, indicate that a free gingival graft which deepened the vestibule and created a wide band of attached and keratinized gingiva can aid in reducing discomfort during oral hygiene practices by the patient, improve gingival health and overall patient satisfaction.

Keywords: periodontics, gingival recessions, periodontal surgery, oral health-related quality of life.

\section{Introduction}

In contemporary dentistry, disease prevention and regeneration have dictated the paradigm shift from the practitioner's reactive approach to disease occurrence in his increasingly educated and demanding patient population to an innovative and proactive patient treatment. Successful periodontal disease control and elimination by skilled dental professionals may leave patients with an esthetic or sensitivity concern. The historical "longer teeth, or no longer teeth" and its sequelae require targeted intervention from today's dental team to prevent lesion progression and improve patient satisfaction.

After surgical technique and patient compliance with oral hygiene and wound care instructions, the patient's physiology, immunology and molecular biology are responsible for the clinical outcome of the procedure. This article will address aspects such as muco-gingival surgery around teeth and implants.

\section{The biological background of wound healing in esthetic periodontal surgery}

The fundamental difference in wound healing of tissues surrounding the tooth compared to other areas of the body is in the interface of the soft tissue to the hard tissue. The different healing patterns after flap surgery have been identified by previous histological and animal studies ${ }^{1-4}$. The surgical elevation of a full thickness flap from the underlying dental and osseous structures leads to a variety of healing mechanisms. Long junctional epithelium constitutes healing by tissue repair and is a hemi-desmosomal adhesion between the connective tissue of the periodontal flap and

\section{*Corresponding author:}

Associate Professor Diana Bronstein, DDS, MS, MS, Associate Director of Predoctoral Periodontology, Department of Periodontology, College of Dental Medicine, Health Profession Division, Nova Southeastern University

3200 South University Drive, Room 7385, Fort Lauderdale, FL-33162-2018, USA

Tel:(954)262 7381/Fax: (954)262-3293,e-mail: db1473@nova.edu 


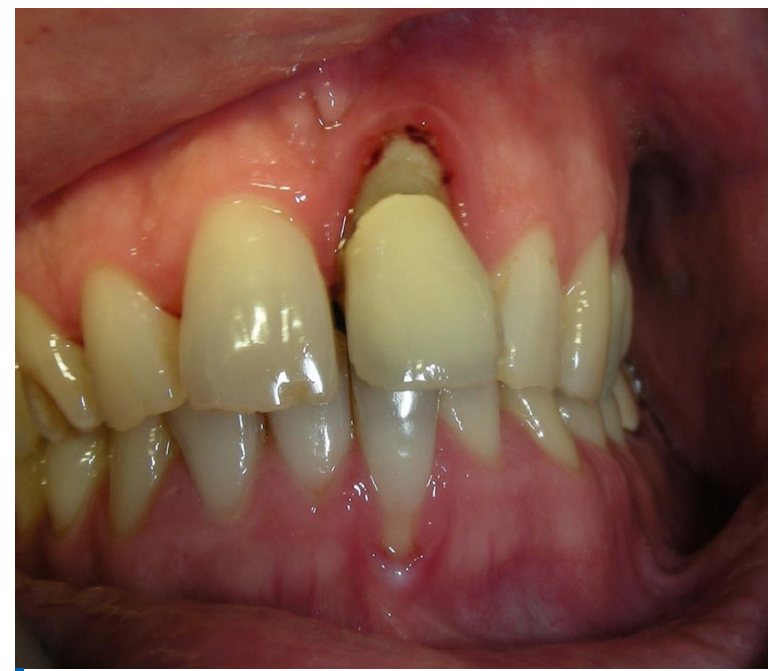

Figure 1. 29 year-old white, male patient presents with fractured, hopelessly involved tooth \#21 (Mucogingival defects of recession and inadequate keratinized gingiva are also present)

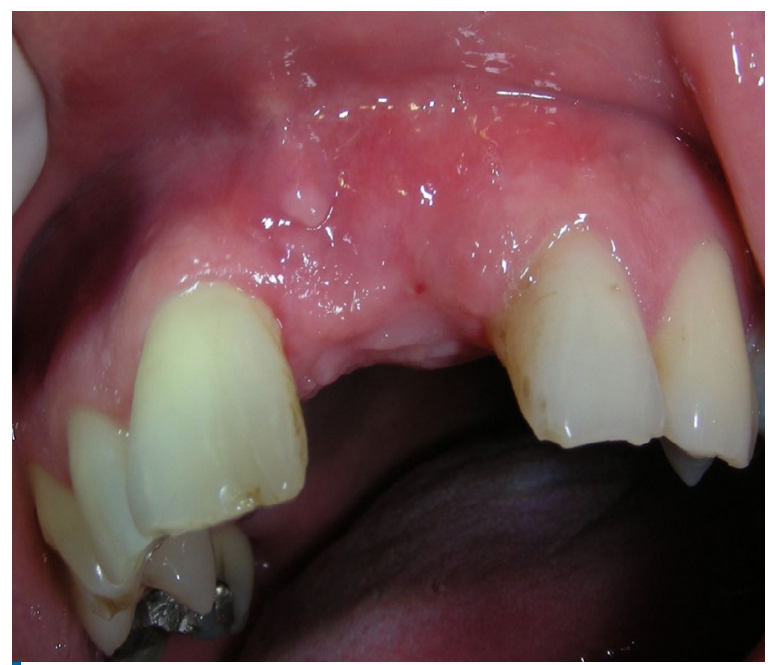

Figure 3. Tooth was extracted and ridge augmented with freeze-dried bone allograft and membrane; 4 months healing. Note keratinized gingiva was still lacking in buccal aspect of \#21 site

the denuded tooth surface. In the apical region of the flap, histological slides have shown repair by connective tissue attachment of the flap to the tooth surface ${ }^{5}$. The approximation of the flap to the tooth is the prerequisite for proper wound healing. In tandem with the patient's compliance, the holding quality of the sutures determined by the skill level of the surgeon will prevent wound healing failure. The down growth of epithelium at the interface along the root surface is a barrier to connective tissue attachment. If a space is allowed between the flap and the tooth during the healing phase the epithelium will occupy that space first. Epithelium proliferates more rapidly than connective or osseous tissue. When the flap is allowed to remain tightly adapted by an undisrupted fibrin clot and adequate sutures during the ten days of initial healing, contact inhibition will stop the epithelium on the outside

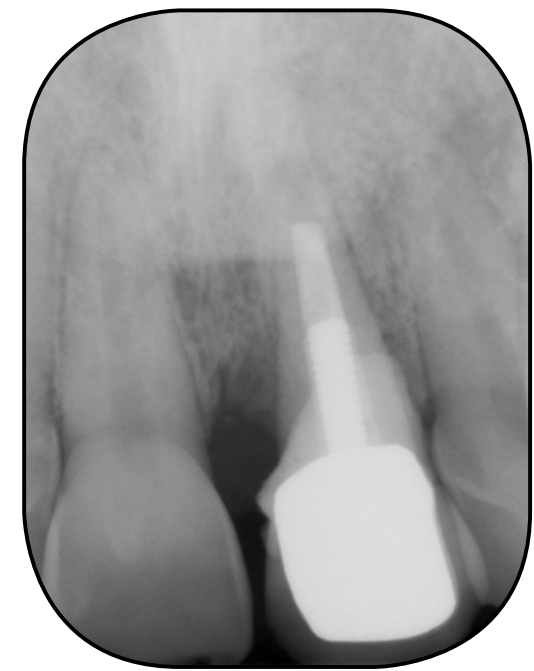

Figure 2. Periapical film showing failing tooth \#21

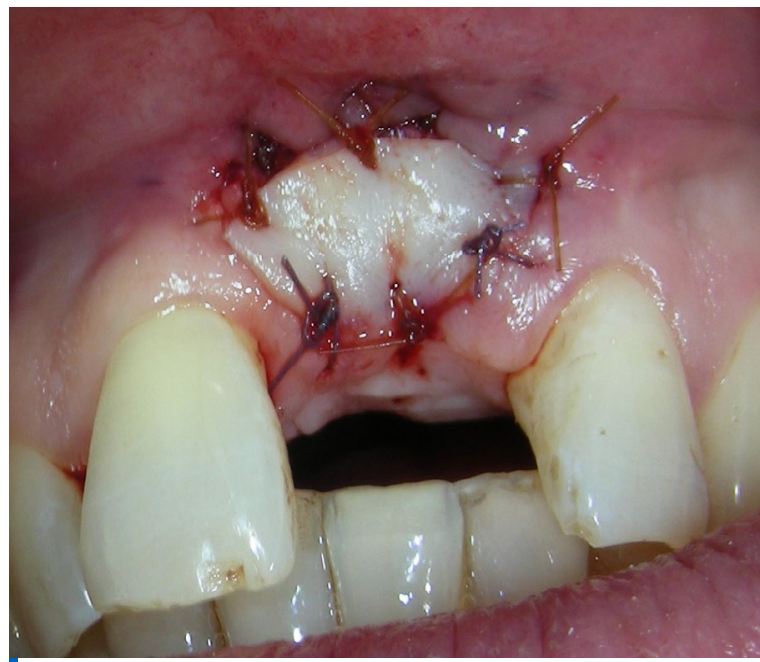

Figure 4. Autogenous free gingival graft completed at \#21 ridge prior to implant placement to augment keratinized gingiva

of the flap from progressing and lining the inside of the flap that is facing the root surface ${ }^{5}$.

Healing by regeneration requires new formation of cementum, bone, periodontal ligament and gingiva with a short epithelial attachment to the tooth. This healing does not occur spontaneously or by resective procedures. Usually biomaterials and modifiers are added to the surgical site to induce or promote regeneration of lost tissues by new technologies. Guided tissue regeneration techniques and soft tissue coverage procedures are used today around teeth and implants.

Soft tissue healing surrounding implants differs from periodontal healing around a tooth. The peri-implant mucosa is isolated from the implant surface by the long junctional epithelium coronally. The supracrestal connective tissue fibers are dense and oriented parallel to the long axis of the implant above the crest of the bone, since insertion of 


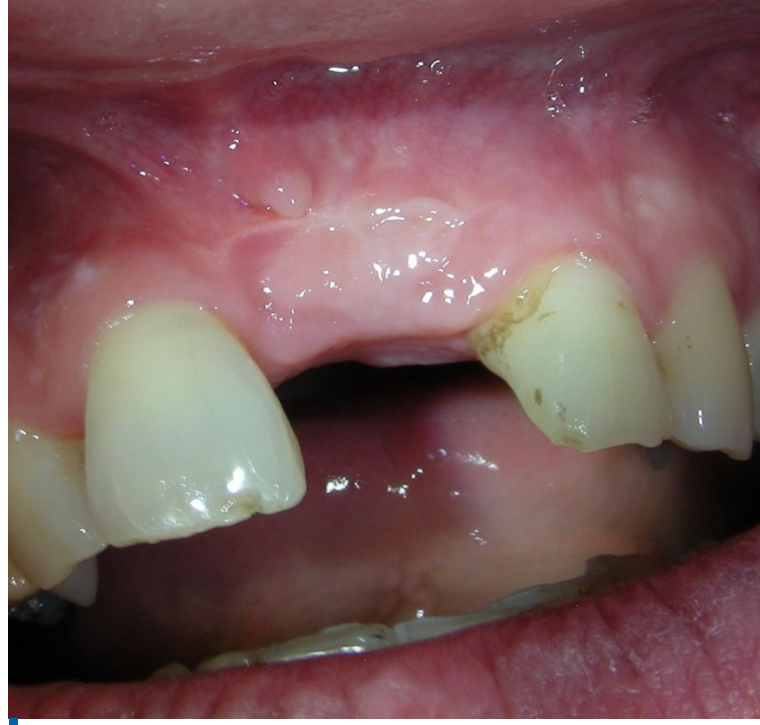

Figure 5. Keratinized graft was allowed to heal 3 months (now 7 months since extraction and bone graft)

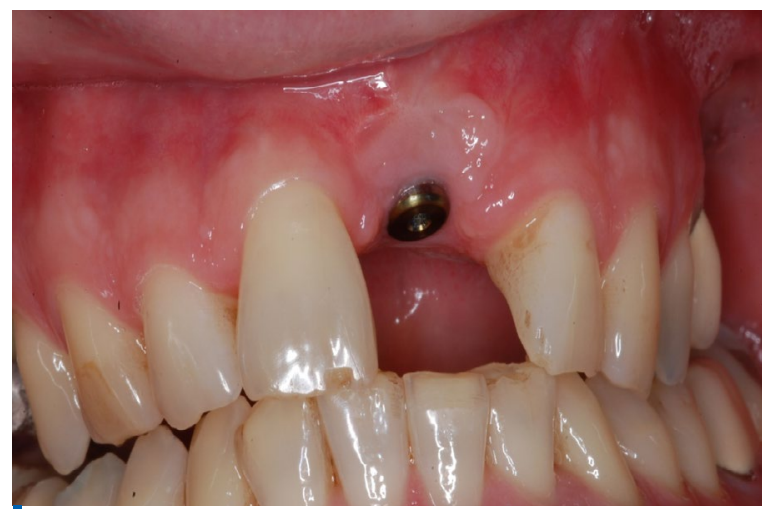

Figure 7. Final torque test and tissue evaluation performed at 4 months

Sharpey fibers into the implant is not possible. Soft tissue procedures are limited in implant dentistry and guided bone regeneration is favored ${ }^{6}$.

\subsection{Soft tissue coverage of dental recessions and implant soft tissue regeneration}

Armitage $^{7}$ defined gingival recession by the apical position of the free gingival margin to the cementoenamel-junction (CEJ) of the tooth or teeth. The indications for periodontal root coverage procedures include: tooth sensitivity, progression of recession, poor oral hygiene maintenance and patient dissatisfaction with appearance ${ }^{8}$. The objective of the corrective surgical procedure is to achieve a color match with the adjacent tissues and symmetrical margins while thickening the tissue to avoid relapse in the absence of inflammation with clinical presentation of probing depth.

Gingiva is a specialized and keratinized mucosa. It consists of the free marginal gingiva around the tooth and the attached gingiva, extending from the free gingival margin to the muco-gingival

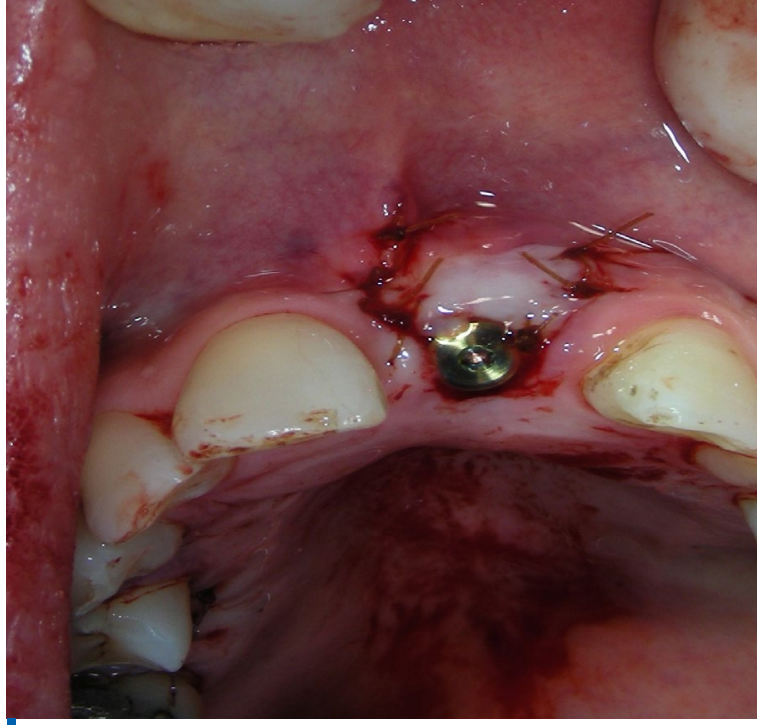

Figure 6. \#21 Implant placed with healing abutment in one-stage procedure and allowed to heal 4 months

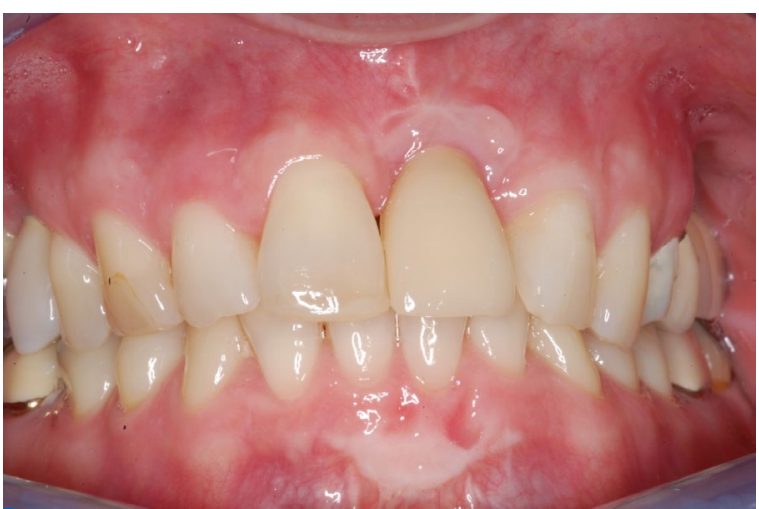

Figure 8. Final restoration clinical photo; note adequate hard and soft tissue contours present on implant site as well as opposing dentition site, which also had a clinical recession presenting. \#24 was treated with a free gingival graft as well

junction. Not all keratinized gingiva is attached, as the free margin and any gingival and periodontal pocketing is unattached by definition. Coincidently, non-keratinized gingiva may be attached, as keratinization is lost at the onset of inflammation, while pocketing has not yet occurred and the gingiva is attached to the tooth. From this biology stems the notion that the lack of keratinized gingiva is compatible with periodontal health, while still attached, in the absence of inflammation ${ }^{26}$.

In the presence of inflammation when patients have difficulty to keep the sites clean or when sensitivity and progressive attachment loss prevail at the recession site, surgical intervention is indicated.

Pedicle and coronally positioned flap, with the base of the flap attached and the coronal part of the flap covering the denuded root surface, with and without autogenous connective tissue graft have demonstrated healing by repair with long junctional epithelium?. Meticulous root debridement and surgical technique have been 


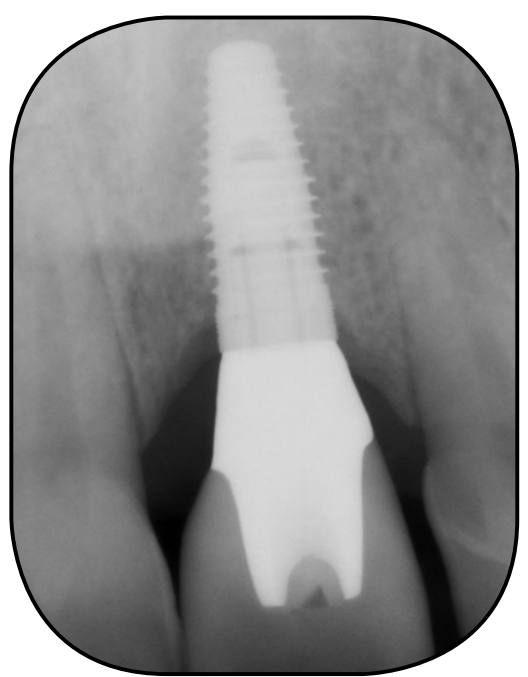

Figure 9. Radiograph showing integrated implant with completed restoration

found to be the determining factor for predictability and success of the procedure ${ }^{10}$. Enamel Matrix Derivative, as Emdogain ${ }^{\circledR}$ has been found to enhance root coverage and healing by repair through connective tissue attachment ${ }^{11,17}$. Root conditioning with Citric Acid has heterogeneous results in soft tissue grafting and improvement of healing by connective tissue attachment versus long junctional epithelium ${ }^{12-16}$.

\subsubsection{Membranes}

When using membranes to augment soft tissue, the amount of connective tissue attachment achieved is similar to an autogenous connective tissue graft that is applied to and covered by a coronolly advanced flap at the recipient site ${ }^{19,20}$. Guided tissue regeneration (GTR) results in better histological outcomes, regardless whether resorbable or non-resorbable membranes used $^{11,21}$.

Guided tissue regeneration requires space and the limitation in root coverage is the surgical space available for clot stabilization and selective cell repopulation ${ }^{1}$.

\subsubsection{Bio-Modifiers}

When using Emdogain ${ }^{\circledR}$, an enamel matrix protein derivative, during guided tissue regeneration procedures or with a connective tissue graft, no additional benefits were observed. However, Emdogain ${ }^{\circledR}$ with a coronally positioned flap alone led to regeneration, which could be histologically verified. The heterogeneous results reported by different studies are due to variation in study design and strength ${ }^{17}$.

\subsubsection{Platelet Rich Plasma and Platelet Derived} Growth Factor (PDGF)

The use of recombinant growth factors has demonstrated regeneration histologically and by micro-computed tomography (CT) with Tricalcium Phosphate in randomized controlled clinical trials 22,23

\subsubsection{Soft Tissue Allo- and Xeno-Graft}

By using a soft tissue substitute in lieu of an autogenous graft, the patient does not have

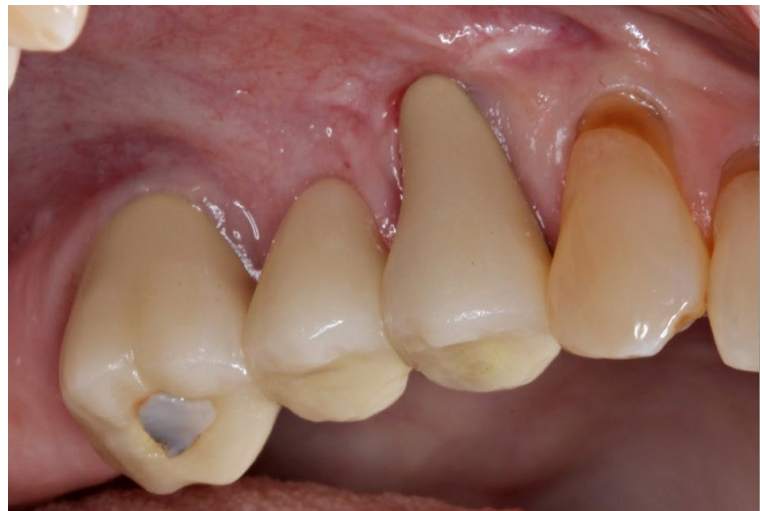

Figure 10. Clinical preoperative photograph of the maxillary right posterior region showing decreased vestibular depth, frenum pull, and lack of keratinized gingiva associated with an FPD with teeth \#16 \& \#14 as abutments and tooth \#15 as a pontic

the increased morbidity of a second surgical donor site ${ }^{25}$. Allogenic acellular dermal matrix and xenogenic collagen matrix (MUCOGRAFT ${ }^{\circledR}$ ) have been used in periodontal plastic surgery and regeneration has been shown ${ }^{24}$. The three dimensional scaffold of the graft allows for space maintenance angiogenesis and fibroblast proliferation. Histology at 6 months showed healing comparable to "scar tissue", dense connective tissue with predominantly elastic fibers ${ }^{27}$.

Free gingival (FGG) and connective tissue (CTG) autografts have been successful in augmenting keratinized tissue around teeth. FGG are taken from an adjacent edentulous ridge or palate and may differ in appearance, presenting esthetic challenges. Since CTG are being mostly covered by the flap of the recipient sites, their esthetic appearance blends with adjacent tissue better during healing, however, post operative shrinkage compromises treatment outcomes.

\subsubsection{Implants}

Not much human histology is currently available on the management of gingival deficiencies on dental implants ${ }^{1}$. Past research has focused on implant surface modification and bone grafting to improve osseous integration and treat periimplantitis.

\section{Cases Reports}

\subsection{Case 1}

\section{Background}

29-year-old white male patient with noncontributory medical history, no known drug allergies, and no social factors presents with chief complaint of a fractured front tooth. Diagnosis upon examination reveals a fractured tooth \#21 with presence of a mucogingival defect (recession) and absence of adequate keratinized gingiva (Figs. 1-2). The prognosis is hopeless. The etiologic factors include trauma and thin morphotype. Treatment plan and completed treatment included: Extraction of tooth \#21 (Fig. 3) with concurrent ridge augmentation using a freeze dried bone allograft and non- 
Table 1. The clinical parameters associated with teeth \# 16 \& \# 14

\begin{tabular}{|c|c|c|c|c|}
\hline \multirow{2}{*}{ Clinical Parameters } & \multicolumn{2}{|c|}{ Baseline } & \multicolumn{2}{c|}{5 months } \\
\hline & $\# 16$ & $\# 14$ & $\# 16$ & $\# 14$ \\
\hline Buccal PD (mm) & $3,2,3$ & $2,3,3$ & $2,1,2$ & $2,2,3$ \\
\hline KT width (mm) & 1 & 0 & 4 & $1-4$ \\
\hline Vitality & - & + & - & + \\
\hline Mobility & - & - & - & - \\
\hline
\end{tabular}
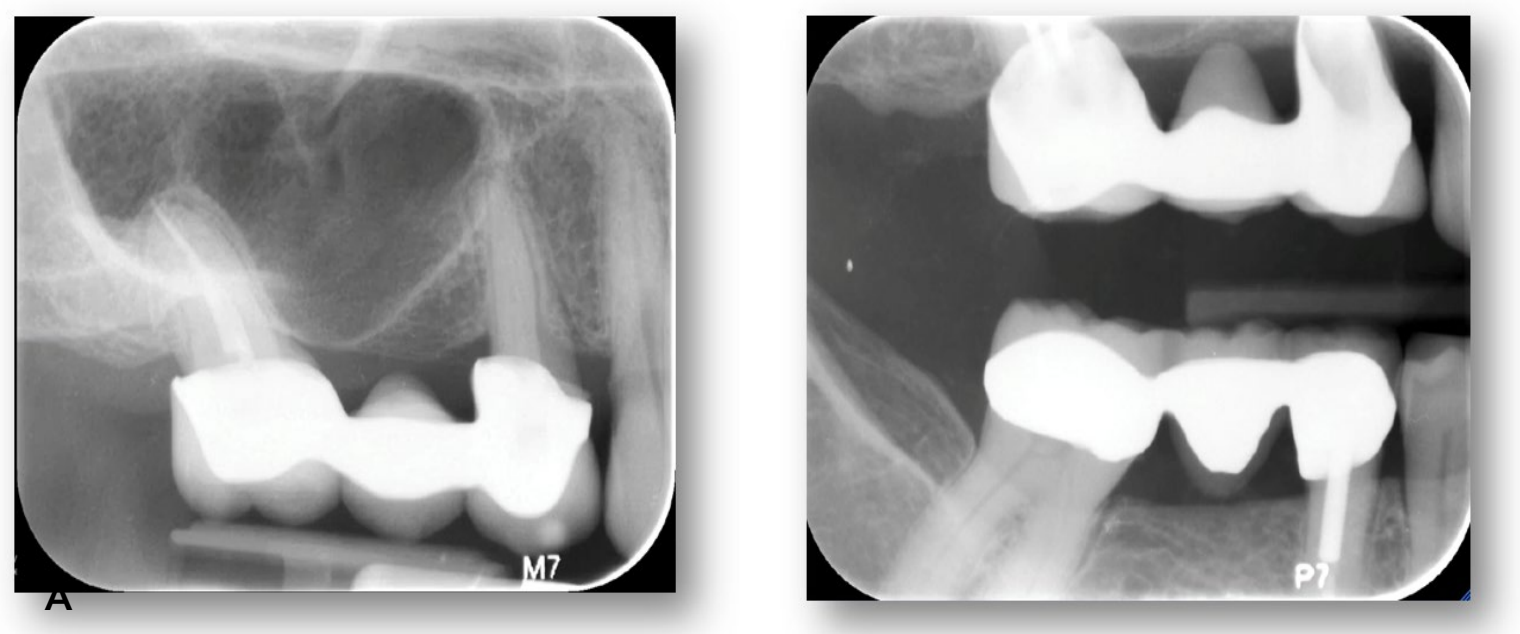

Figures $11 \mathrm{a}$ and $11 \mathrm{~b}$. An Intraoral periapical and bitewing radiograph of the maxillary right posterior region

absorbable membrane (removed at 1 month). The site was allowed to heal while the patient was provisionalized with an essix retainer for 4 months. A keratinized autogenous free gingival graft was performed to augment the buccal gingiva of the \#21 site lacking sufficient keratinized tissue (Fig. 4). After 3 months of healing (Fig. 5) a dental implant was placed $(4.3 \times 11.5$ Nobel Replace Select Tapered Groovy RP) with healing abutment via use of a surgical prosthetic guide (Fig. 6). The implant was allowed to heal for 4 months before restoration (Fig. 7). A new radiograph and torque test were performed at 4 months and the implant was restored with a cement-retained crown (Figs. 8-9).

\subsection{Case 2}

\section{Background}

A 77-year-old female non-smoker with controlled hypertension presented to the Post Graduate Periodontology Clinic, Nova Southeastern University, Fort Lauderdale, Florida, in February 2016 with a chief complaint of "sensitive gums and discomfort when brushing" associated with an FPD in the maxillary right posterior region (\#16-
X-14). Intraoral examination revealed good oral hygiene, thin gingival biotype with generalized lack of keratinized gingiva, and generalized mild to moderate gingival recession. In the maxillary right posterior, there was decreased vestibular depth and lack of keratinized gingiva associated with an FPD with teeth \#16 \& \#14 as abutments and tooth \#15 as a pontic (Fig.10).

The FPD (fixed partial denture) was fabricated by her previous dentist 2 years ago and she recently had RCT (root canal treatment) on tooth \#16 before presenting to the Periodontics Department. The clinical parameters associated with teeth \#16 \& \#14 are described in Table 1.

An intraoral periapical and bitewing radiograph of the region are shown in Fig. 11. The patient was informed of the bulky overhanging margins of the FPD, however, refused to proceed with any prosthetic treatment at this time. It was decided to use a Free Gingival Graft harvested from the palate to create a band of attached keratinized gingiva and increase the vestibular depth. Witten informed consent for periodontal surgery was obtained from the patient.

Case Management 


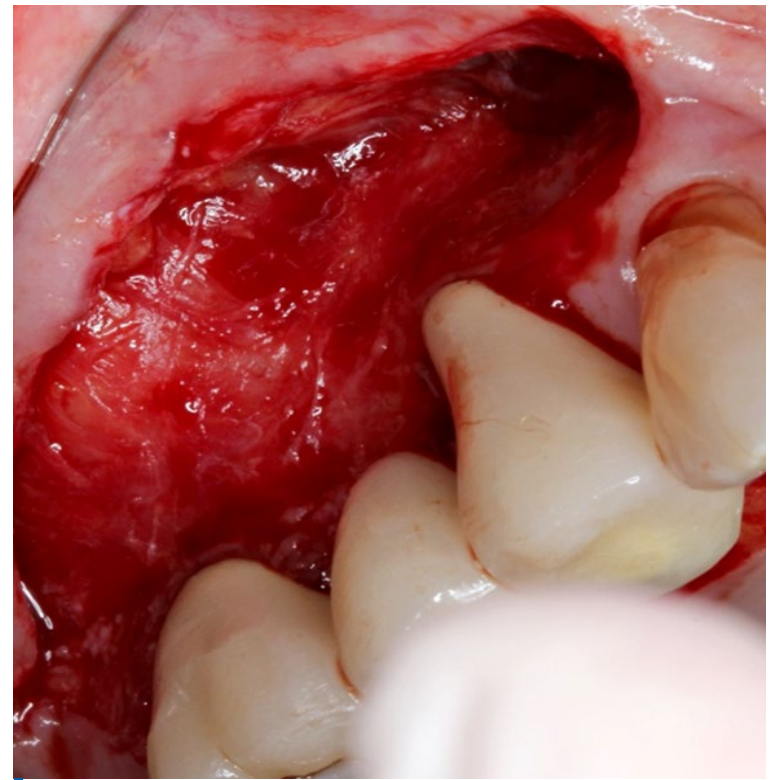

Figure 12. Clinical intraoperative photograph showing the recipient bed around the teeth and in the pontic region

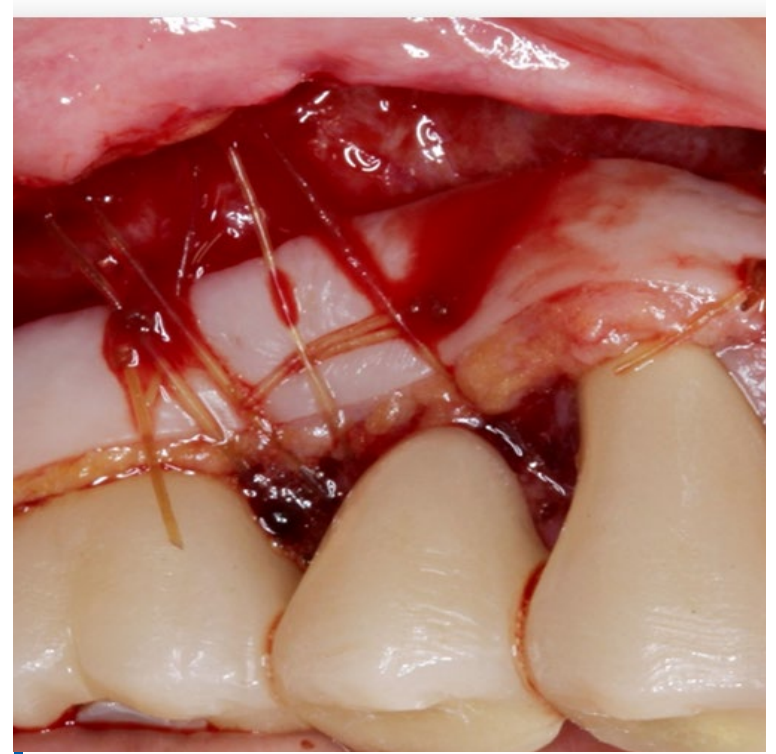

Figure 14. Clinical intraoperative photograph showing the graft stabilized and immobilized via periosteal and single interrupted sutures

The attached keratinized gingiva is dense, resilient and tightly attached to the underlying tooth and bone, while the alveolar mucosa is thin, mobile, and apparently less capable of withstanding the functional stresses of mastication and oral hygiene practiced by the patient. The autogenous free gingival graft is a predictable surgical procedure to increase the width of keratinized attached gingiva, eliminate frenum and muscle pull, and to extend the vestibular depth depth ${ }^{18}$.

After the administration of anesthesia to the recipient site via local infiltrations on the buccal and palatal aspect of the maxillary right posterior region, periodontal curettes were used for subgingival debridement of the root surfaces of teeth \#16 \& \#14 without damaging the crown

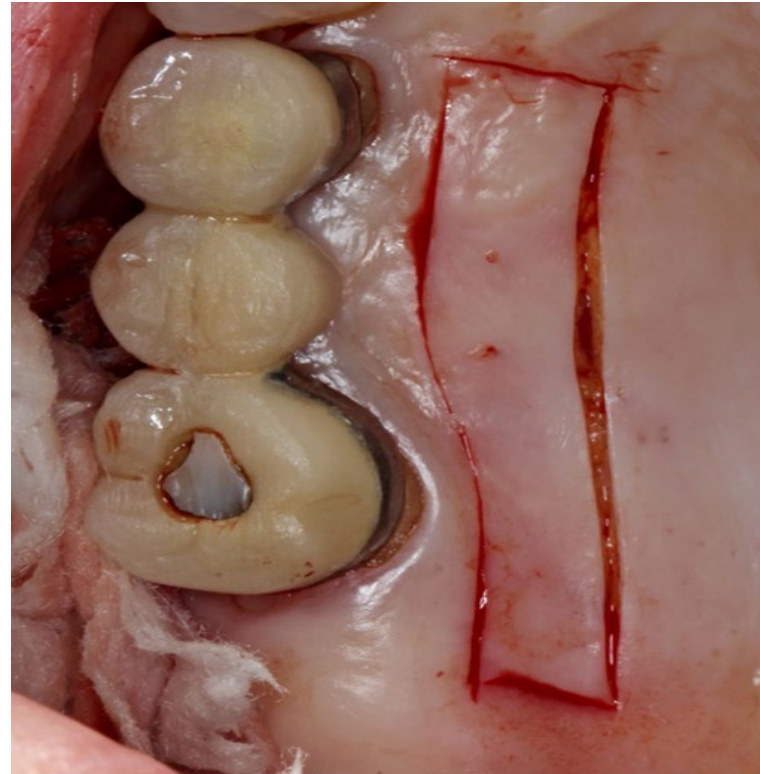

Figure 13. Clinical intraoperative photograph showing the donor site (right side of palate). An outline was made with a new $15 \mathrm{c}$ blade

margins, then the FPD was wiped with gauze soaked in $0.12 \%$ chlorhexidine for 30 seconds. Subsequently, the recipient site's epithelium, CT, and muscle fibers were sharply dissected down to the periosteum using $15 \mathrm{c}$ and 12 blades and microscissors to create a large recipient bed around the teeth and in the pontic region (Fig. 12). Immediately after, a Free Gingival Graft was harvested from the right side of the palate using a new $15 \mathrm{c}$ blade (Fig. 13). The graft was immediately transferred to the recipient site, which was stabilized and immobilized via periosteal and single interrupted sutures with 4.0 chromic gut sutures (Fig. 14). Finally, tactile pressure was placed over the graft to remove any blood clots between the graft and recipient bed and to achieve close adaptation of the graft. No periodontal dressing was used to cover the graft and the patient was instructed to follow a liquid diet for the first 24 hours, followed by a soft diet for the remaining week and eat on the left side only. Patient was instructed to refrain from oral hygiene practices in the surgical site while rinsing with $0.12 \%$ chlorhexidine gluconate (three times daily) for 2 weeks, take $500 \mathrm{mg}$ Amoxicillin (every 8 hours) for 7 days and 800 mg lbuprofen (every 8 hours) as needed for discomfort. The postoperative follow-ups were conducted at 1 (Fig. 15 A \& B), 3 (Fig. 16 A), and 6 weeks (Fig. 16 B).

\section{Clinical Outcomes}

Healing was uneventful at both the donor and recipient sites. At the 1-week follow-up only visual examination was performed which revealed slight erythema and edema consistent with normal postsurgical healing and no swelling or infection was present (Fig. 15). At the 3- and 6-week follow-ups the surgical area was irrigated gently with $0.12 \%$ chlorhexidine and plaque surrounding the FPD was removed with Q-tips soaked in chlorhexidine (Fig. $16 \mathrm{~A}$ and Fig. $16 \mathrm{~B}$ ). 

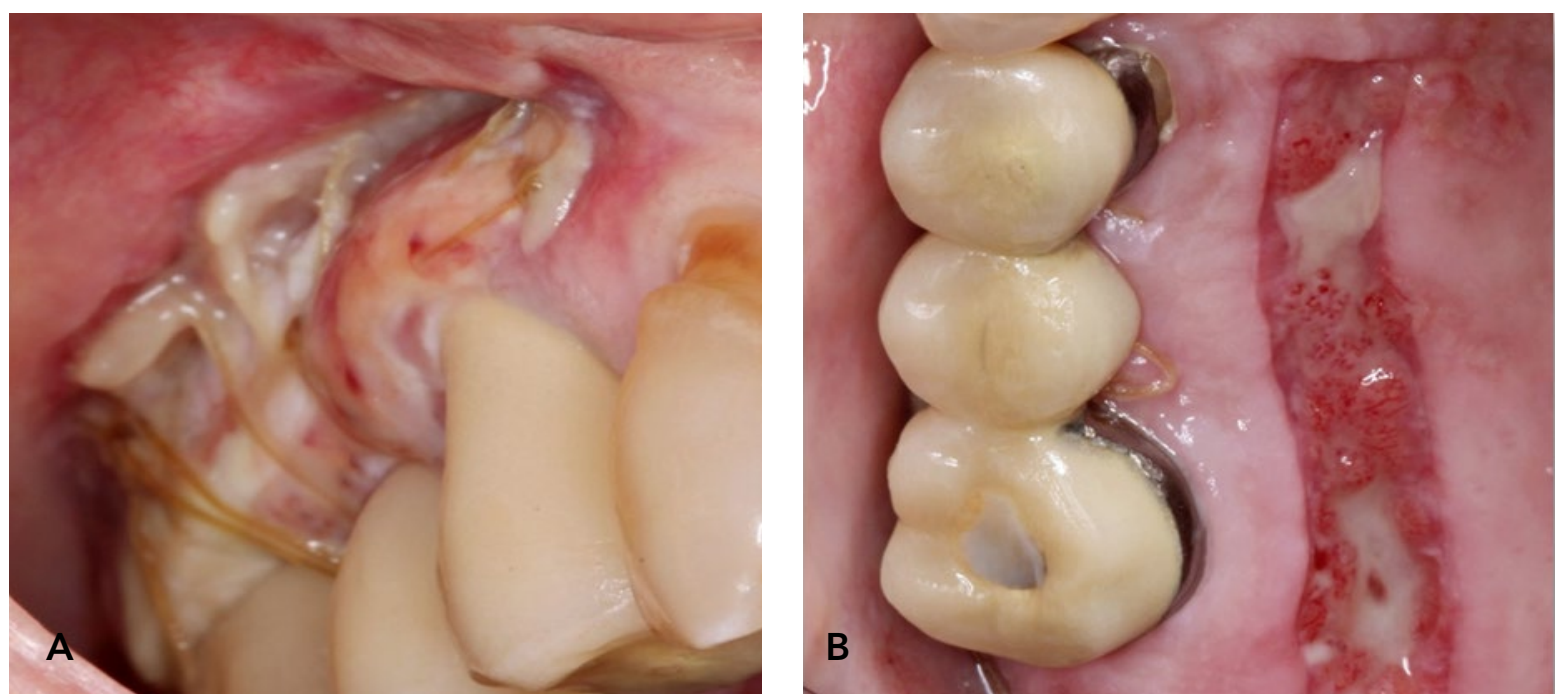

Figures $15 \mathrm{a}$ and $\mathbf{1 5 b}$. Clinical photographs of recipient and donor sites 1 week after surgery
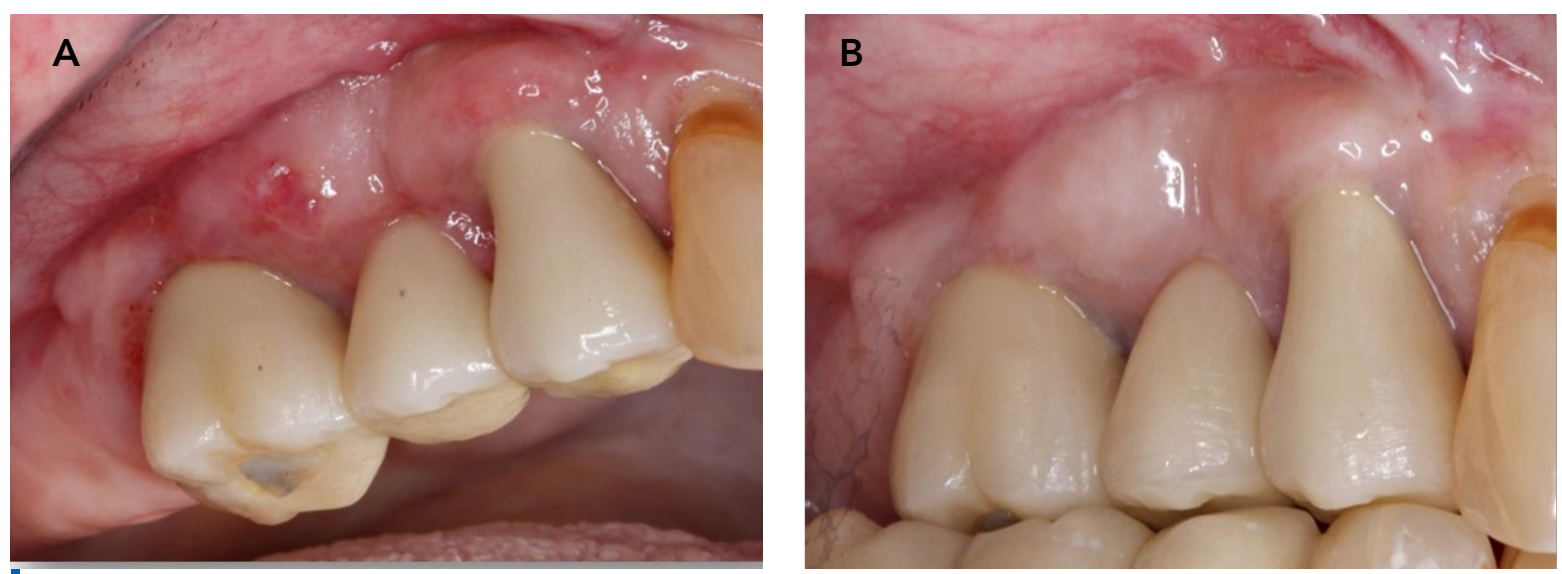

Figures $16 \mathrm{a}$ and $16 \mathrm{~b}$. Clinical photographs of recipient site 3 weeks $(A) \& 6$ weeks $(B)$ after surgery
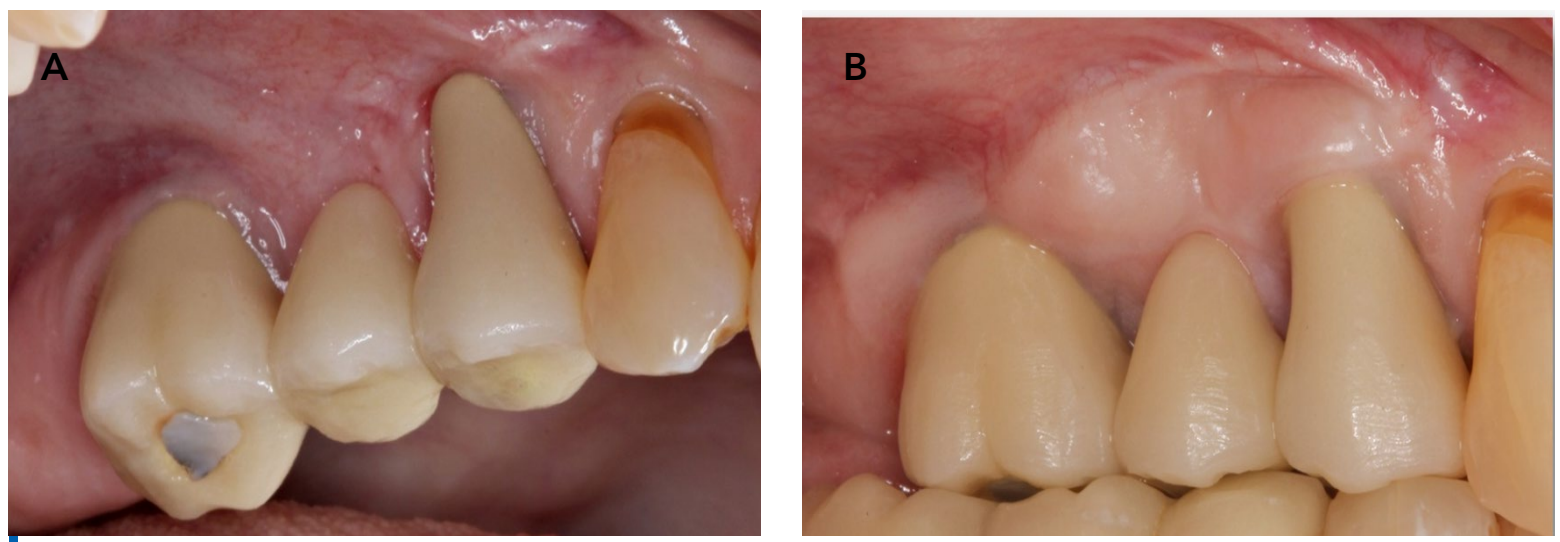

Figures $17 \mathrm{a}$ and $17 \mathrm{~b}$. Clinical photograph of recipient site preoperative and 5 months post-surgery

At the 5 month follow up, the patient reported no gingival discomfort when brushing the maxillary right posterior region. The clinical examination revealed a deepened vestibule and gain in attached and keratinized gingiva around the FPD abutments \#16 \& \#14 and facial aspect of the pontic. The probing depths ranged from 1-3mm surrounding the FPD with no BOP (Fig. 17 B, Table 1). Conclusion

In cases with lack of keratinized attached gingiva, the results of the present case report indicate that a free gingival graft which deepened the vestibule and created a wide band of attached keratinized gingiva can aid in reducing discomfort during oral hygiene practices by the patient.

\subsection{Case 3}

\section{Clinical Presentation}

A 35-year-old male non-smoker with noncontributory medical history presented to the Post Graduate Periodontology Clinic, Nova Southeastern University, Fort Lauderdale, Florida. In April 2016 with a chief complaint of "my dentist 


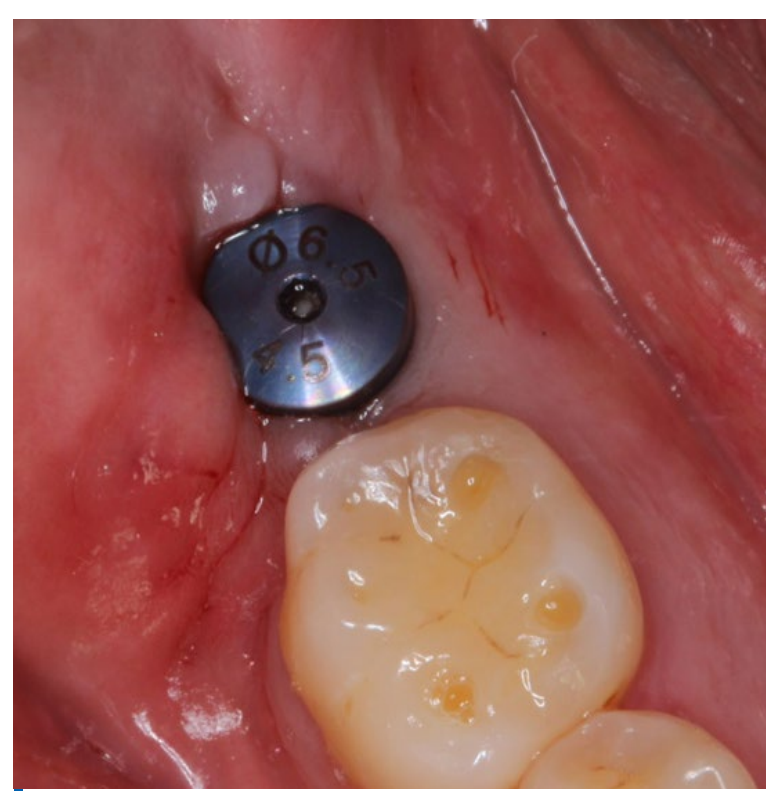

Figure 18. Clinical preoperative photograph of the mandibular right posterior region showing decreased vestibular depth and lack of keratinized gingiva associated with implant \#47

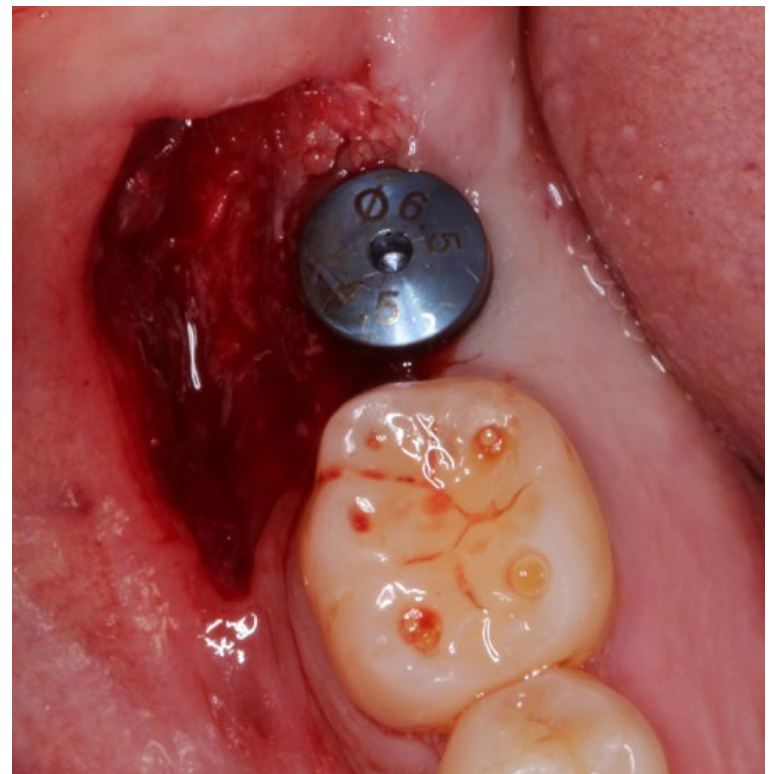

Figure 20. Clinical intraoperative photograph showing the recipient bed on the buccal aspect of implant \#47

said I may need some gum treatment around my implant." Intraoral examination revealed good oral hygiene, an intact dentition with only one missing tooth \#47, which was replaced by a dental implant. Specifically, in the mandibular right posterior, there was lack of keratinized attached gingiva on the buccal aspect of the implant \#47 (Fig. 18). An intraoral periapical radiograph of the region is shown in Fig. 19. The patient also reported discomfort when brushing the healing abutment and expressed concern if this discomfort would be present after his dentist provides the final implant crown.

The clinical findings were explained to the patient

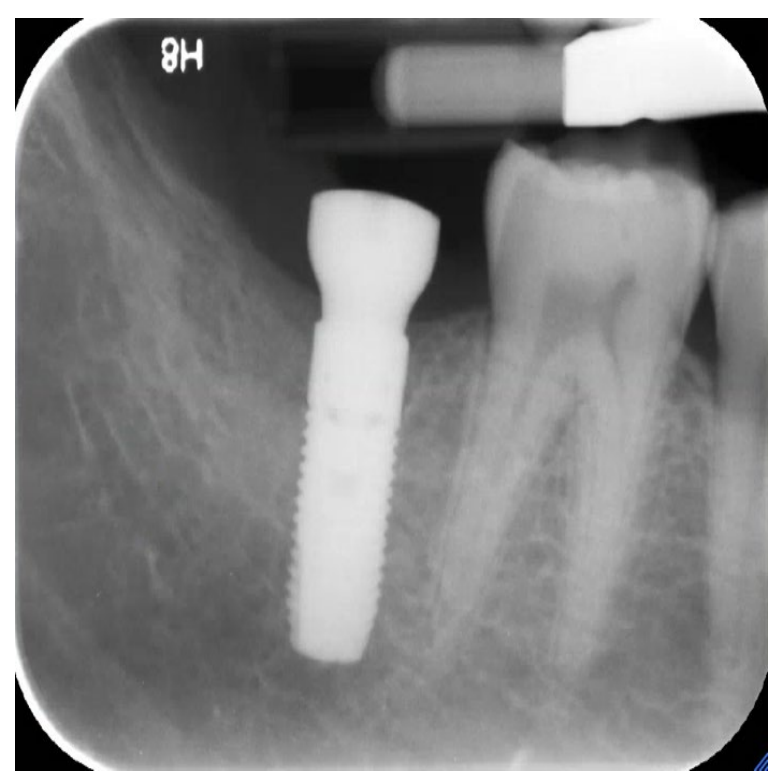

Figure 19. An intraoral periapical radiograph of the mandibular right posterior region showing implant \#47 with a healing abutment in place

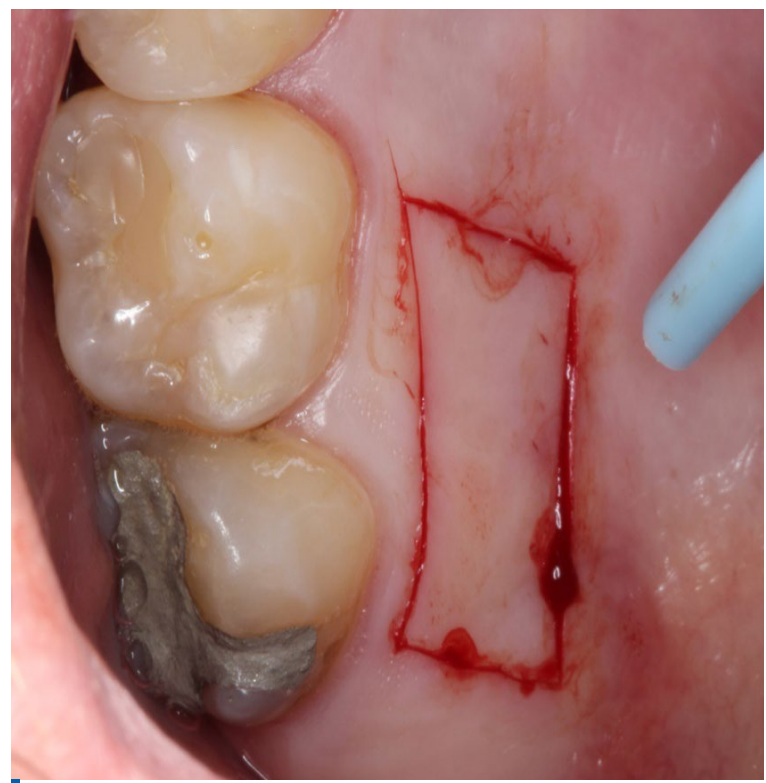

Figure 21. Clinical intraoperative photograph showing the donor site (right side of palate). An outline was made with a new 15c blade

and what was recommended was to use a Free Gingival Graft harvested from the palate to create a band of attached keratinized gingiva and increase the vestibular depth around the implant. A written informed consent for periodontal surgery was obtained from the patient.

\section{Case Management}

After the administration of anesthesia to the recipient site via local infiltrations on the buccal and lingual aspect of the mandibular right posterior region, the recipient site's epithelium, $\mathrm{CT}$, and muscle fibers were sharply dissected down to the periosteum using $15 c$ and 12 blades 


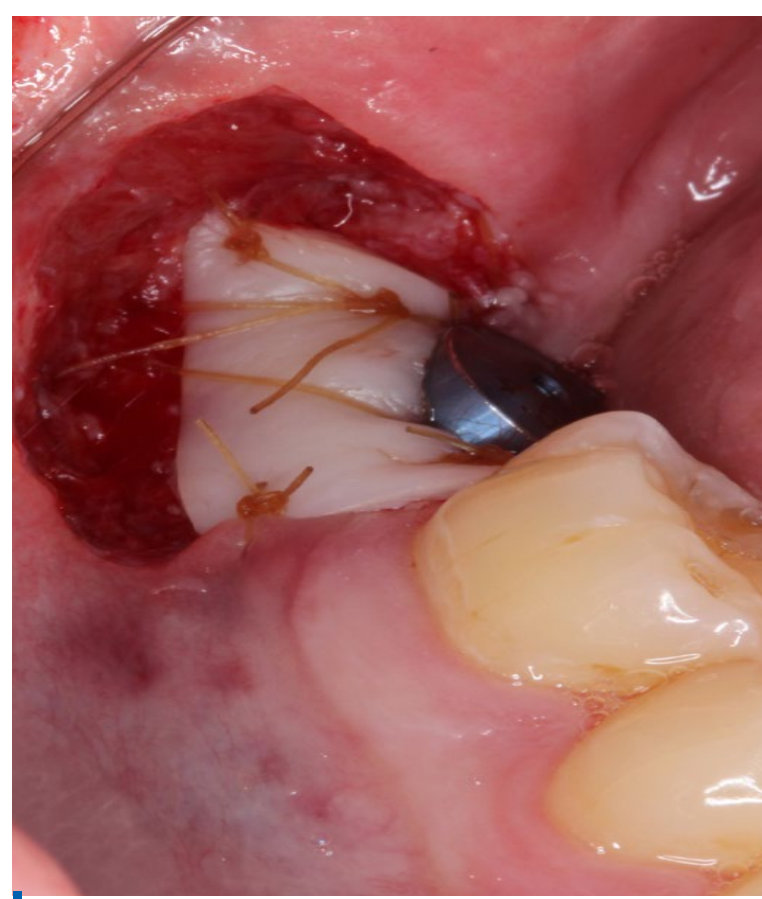

Figure 22. Clinical intraoperative photograph showing the graft stabilized and immobilized via periosteal and single interrupted sutures

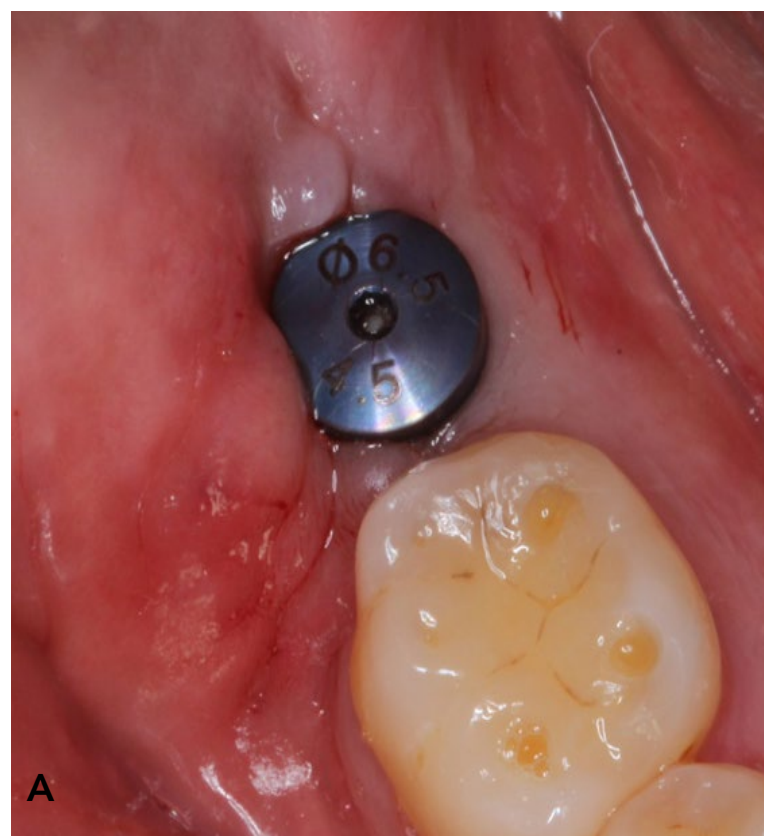

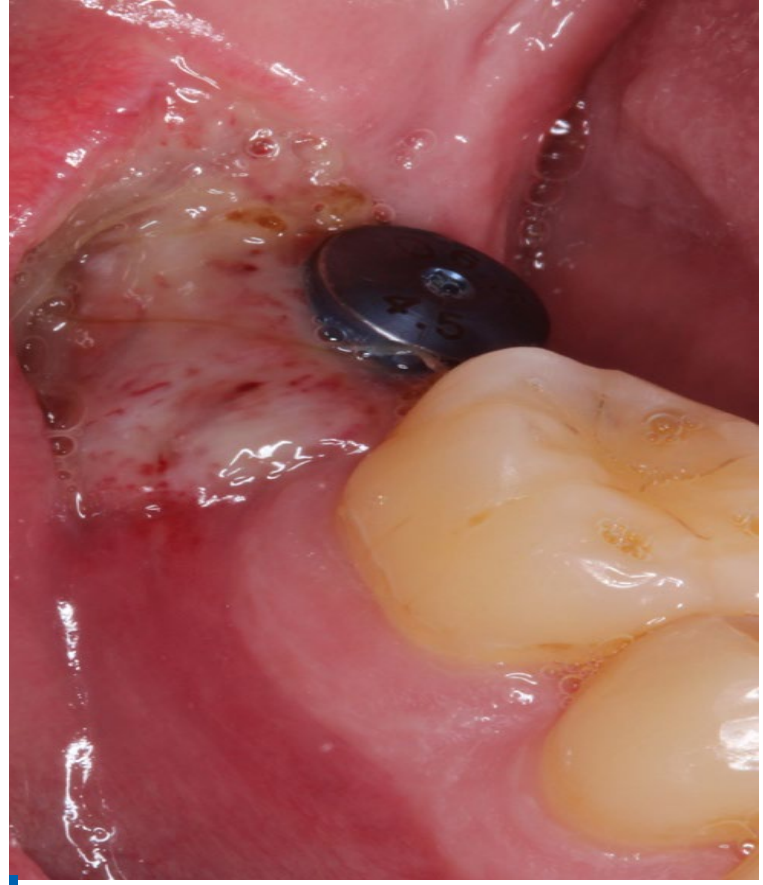

Figure 23. Clinical photograph of the recipient site 1 week after surgery

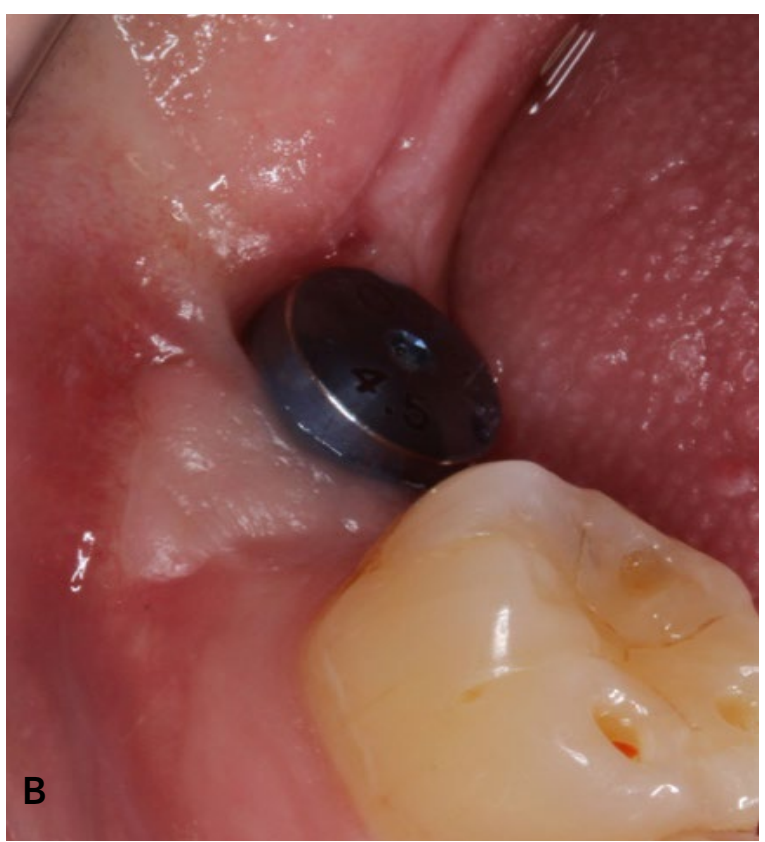

Figures 24a and 24b. Clinical photographs of the recipient site preoperative and 8-weeks after surgery

and micro-scissors to create a large recipient bed around the buccal aspect of healing abutment (Fig. 20). Immediately after, a Free Gingival Graft was harvested from the right side of the palate using a new $15 \mathrm{c}$ blade (Fig. 21). The graft was immediately transferred to the recipient site, which was stabilized and immobilized via periosteal and single interrupted sutures with 4.0 chromic gut sutures (Fig. 22). Finally, tactile pressure was placed over the graft to remove any blood clots between the graft and recipient bed and to achieve close adaptation of the graft. No periodontal dressing was used to cover the graft and the patient was instructed to follow a liquid diet for the first 24 hours, followed by a soft diet for the remaining week and eat on the left side only. The patient was instructed to refrain from oral hygiene practices in the surgical site while rinsing with $0.12 \%$ chlorhexidine gluconate (three times daily) for 2 weeks, take 500 mg Amoxicillin (every 8 hours) for 7 days and $800 \mathrm{mg}$ lbuprofen (every 8 hours) as needed for discomfort. The postoperative followups were conducted at 1 and 8 weeks.

\section{Clinical Outcomes}

Healing was uneventful at both the donor and recipient sites. At the 1-week follow-up only visual 
examination was performed which revealed slight erythema and edema consistent with normal post-surgical healing and no swelling or infection was present (Fig. 23). At the 8-week follow-up the surgical area was irrigated gently with $0.12 \%$ chlorhexidine and plaque covering the healing abutment and adjacent tooth was removed with Q-tips soaked in chlorhexidine. At the 8-week follow up, the patient reported no gingival discomfort when brushing the healing abutment with a soft toothbrush. Clinical examination revealed a deepened vestibule and gain in attached and keratinized gingiva on the buccal aspect of the implant. Fig. $24 \mathrm{~A}$ and $\mathrm{B}$ show the preoperative and 8 -week postoperative clinical presentation.

\section{Conclusions}

While the need for keratinized tissue to prevent the occurrence of recessions or to achieve complete recession coverage in the literature is controversial, the literature supports higher predictive values for home care and plaque control combined with patient compliance in regard to maintenance intervals, rather than keratinized tissue widths. Soft tissue thickness of at least $0.8 \mathrm{~mm}$ is required to achieve complete root coverage when using a coronolly positioned flap, while tissue thinner than $0.8 \mathrm{~mm}$ more often lead to incomplete recession coverage ${ }^{28}$. Recessions treated with guided tissue regenerationare more successfully covered in thick biotype patients ${ }^{29}$. Modifying tissue thickness may improve complete root coverage regardless of

\section{REFERENCES}

1. Vignoletti $F$, Nunez J, Sanz M. Soft tissue regeneration in the oral cavity: review of the current literature on scaffolds, cells and biologicals. J Clin Periodontol. 2014;41(Suppl. 15):S23-S35. doi: 10.1111/jcpe.12191.

2. Sculean A, Gruber R, Bosshardt DD. Soft tissue wound healing around teeth and dental implants. J Clin Periodontol. 2014;41(Suppl. 15):S6-22. doi: 10.1111/jcpe.12206.

3. Susin C, Fiorini T, Lee J, De Stefano JA, Dickinson DP, Wikesjö UM. Wound healing following surgical and regenerative periodontal therapy. Periodontol 2000.2015;68(1):83-98. doi: 10.1111/prd.12057. 4. Suzuki JB, Bronstein D. Ridge preservation and advanced bone grafting for the general practitioner. J Mass Dent Soc. 2011;60(3):40-42.

5. Susin C, Wikesjö UM. Regenerative periodontal therapy: 30 years of lessons learned and unlearned. Periodontol 2000. 2013;62(1):232242. doi: 10.1111/prd.12003

6. Berglundh T, Abrahamsson I, Welander M, Lange NP, Lindhe J. Morphogenesis of the peri-implant mucosa: an experimental study in dogs. Clin Oral Implants Res. 2007;18(1):1-8.

7.Armitage GC. Development of a classification system for periodontal diseases and conditions. Ann Periodontol. 1999;4(1):1-6.

8. Susin C, Dalla Vecchia CF, Oppermann RV, Haugejorden O, Albandar JM. Periodontal attachment loss in an urban population of Brazilian adults: effect of demographic, behavioral, and environmental risk indicators. J Periodontol. 2004;75(7):1033-1041.

9. Chambrone L, Sukekava F, Araújo MG, Pustiglioni FE, Chambrone LA, Lima LA. Root-coverage procedures for the treatment of localized recession-type defects: a Cochrane systematic review. J Periodontol. 2010;81(4):452-478. doi: 10.1902/jop.2010.090540.

10. Caffesse RG, Kon S, Castelli WA, Nasjleti CE. Revascularization following the lateral sliding flap procedure. J Periodontol. 1984;55(6):352-358.

11. Cairo F, Pagliaro U, Nieri M. Treatment of gingival recession with coronally advanced flap procedures: a systematic review. J Clin Periodontol. 2008;35(8 Suppl):136-162. doi: 10.1111/j.1600051X.2008.01267.x. keratinized tissue width or depth of recession". Maintaining blood supply to the graft is crucial for success of procedure. Vascularization can be recruited from the periosteal bed for the thick free gingival graft or in case of connective tissue graft and allograft also from the covering flap. The double blood supply for the connective tissue graft contributes to its success, when compared to thick free gingival graft. Flap retraction apically during healing due to tension from lack of mobilization or suturing, will reduce success of procedures ${ }^{28}$. Flap design and suturing technique must be planed accordingly. Coronally advanced flaps are not indicated in cases of shallow vestibules as flap retraction is increased and recessions reoccur more often. Tunneling procedures avoid recurrent recessions and preserve the papillae. Ultimately, adequate case selection will determine surgical and clinical success as it is the experience and the skill of the practitioner to determine indication and technique details ${ }^{29,30}$. The most important prognostic factor for success of surgical and nonsurgical cosmetic and periodontal recession treatment is patient compliance with home care, maintenance and atraumatic tooth brush techniques.

\section{Acknowledgments}

The author declares no conflict of interest related to this study. There are no conflicts of interest and no financial interests to be disclosed.

12. Bruno JF, Bowers GM. Histology of a human biopsy section following the placement of a subepithelial connective tissue graft. Int J Periodontics Restorative Dent. 2000;20(3):225-231.

13. Gottlow J, Nyman S, Karring T, Lindhe J. Treatment of localized gingival recessions with coronally displaced flaps and citric acid. An experimental study in the dog. J Clin Periodontol. 1986;13(1):57-63. 14. Goldstein M, Boyan BD, Cochran DL, Schwartz Z. Human histology of new attachment after root coverage using subepithelial connective tissue graft. J Clin Periodontol. 2001;28(7):657-662.

15. Harris RJ. Human histologic evaluation of root coverage obtained with a connective tissue with partial thickness double pedicle graft. A case report. J Periodontol. 1999;70(7):813-821.

16. Pasquinelli $\mathrm{KL}$. The histology of new attachment utilizing a thick autogenous soft tissue graft in an area of deep recession: a case report. Int J Periodontics Restorative Dent. 1995;15(3):248-257.

17. Miron RJ, Sculean A, Cochran DL, Froum S, Zucchelli G, Nemcovsky C, Donos $\mathrm{N}$

Lyngstadaas SP, Deschner J, Dard M, Stavropoulos A, Zhang Y, Trombelli L, Kasaj A, Shirakata Y, Cortellini P, Tonetti M, Rasperini G, Jepsen S, Bosshardt DD. Twenty years of enamel matrix derivative: the past, the present and the future. J Clin Periodontol. 2016;43(8):668-83. doi: 10.1111/jcpe.12546.

18. Nabers JM. Free gingival grafts. Periodontics. 1966;4(5):243-245. 19. Casati MZ, Sallum EA, Caffesse RG, Nociti FH Jr, Sallum AW, Pereira $\mathrm{SL}$. Guided tissue regeneration with a bioabsorbable polylactic acid membrane in gingival recessions. A histometric study in dogs. J Periodontol. 2000;71(2):238-248.

20. Weng $D$, Hürzeler MB, Quiñones CR, Pechstadt B, Mota L, Caffesse RG. Healing patterns in recession defects treated with ePTFE membranes and with free connective tissue grafts. A histologic and histometric study in the beagle dog. J Clin Periodontol. 1998;25(3):238-245.

21. Roccuzzo M, Bunino M, Needleman I, Sanz M. Periodontal plastic surgery for treatment of localized gingival recessions: a systematic review. J Clin Periodontol. 2002;29 Suppl. 3:178-194; discussion 195-196. 
22. McGuire MK, Scheyer ET, Schupbach P. Growth factor-mediated treatment of recession defects: a randomized controlled trial and histologic and microcomputed tomography examination. J Periodontol. 2009;80(4):550-564. doi: 10.1902/jop.2009.080502.

23. McGuire MK, Scheyer T, Nevins M, Schupbach P. Evaluation of human recession defects treated with coronally advanced flaps and either purified recombinant human platelet-derived growth factorBB with beta tricalcium phosphate or connective tissue: a histologic and microcomputed tomographic examination. Int J Periodontics Restorative Dent. 2009;29(1):7-21.

24. Camelo M, Nevins M, Nevins ML, Schupbach P, Kim DM. Treatment of gingival recession defects with xenogenic collagen matrix: a histologic report. Int J Periodontics Restorative Dent. 2012;32(2):167-173.

25. Griffin TJ, Cheung WS, Zavras Al, Damoulis PD. Postoperative complications following gingival augmentation procedures. J Periodontol. 2006;77(12):2070-2079.

26. Kennedy JE, Bird WC, Palcanis KG, Dorfman HS. A longitudinal evaluation of varying widths of attached gingiva. J Clin Periodontol. 1985;12(8):667-675.

27. Wei PC, Laurell L, Geivelis M, Lingen MW, Maddalozzo D. Acellular dermal matrix allografts to achieve increased attached gingiva. Part 1. A clinical study. J Periodontol. 2000;71(8):1297-1305.

28. Burkhardt R, Lang NP. Fundamental principles in periodontal plastic surgery andmucosal augmentation--a narrative review. J Clin Periodontol. 2014;41 Suppl 15:S98-S107. doi: 10.1111/jcpe.12193.

29. Sanz M, Simion M; Working Group 3 of the European Workshop on Periodontology.Surgical techniques on periodontal plastic surgery and soft tissue regeneration: consensusreport of Group 3 of the 10th European Workshop on Periodontology. J Clin Periodontol.2014;41 Suppl 15:S92-S97. doi: 10.1111/jcpe.12215.

30. Greenwell H, Fiorellini J, Giannobile W, Offenbacher S, Salkin L, Townsend C,Sheridan P, Genco R; Research, Science and Therapy Committee. Oral reconstructive andcorrective considerations in periodontal therapy. J Periodontol. 2005;76(9):1588-1600. Review.

\section{Diana BRONSTEIN \\ DDS, MS, MS, DABP, FICOI, DICOI Associate Professor, Director Department of Periodontology College of Dental Medicine Nova Southeastern University Fort Lauderdale, FL-33162-2018, USA

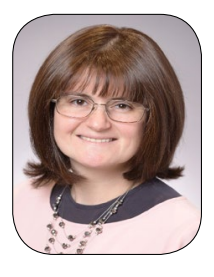

Diana Bronstein, DDS, MS, MS, DABP, FICOI, DICOI is an Associate Professor and the Associate Predoctoral Periodontology Program Director for the Periodontology Department at Nova Southeastern University, College of Dental Medicine. She is licensed in the US as well as in the EU and is double boarded as Diplomate of the American Academy of Periodontology and Diplomate and Fellow of the International Congress of Oral Implantology. Her Specialty Certification is in Periodontology and Oral Implantology from Temple University, Kornberg School of Dentistry, as well as her Master of Science in Oral Biology. Her Master of Science in Medical Education is from the Nova Southeastern University. She has co-authored book chapters in academic textbooks, scientific articles and presented surgical and non-surgical periodontal treatment and Guided Bone and Tissue Regeneration.

\section{Orestions}

\section{Which of the following tissues proliferates the fastest?}

$\square$ a. Epithelium;

ab. Connective Tissue;

ac. Bone;

$\square$ d. They all proliferate at an equal speed.

\section{Healing by true Periodontal Regeneration, involves formation of the following:}

口a. Cementum;

ab. PDL;

ac. Bone;

ad. All of the above.

\section{All of the following are advantages of Free Gingiva Grafts, except:}

$\square$ a. Increase the width of keratinized gingiva;

ab. Increase the thickness of the gingiva;

$\square$ c. Deepen the vestibule;

$\square d$. Superior esthetics and color match.

\section{As described in the previous clinical cases, the patient was instructed to refrain from oral hy- giene practices in the grafted area for how long?}

घa. 24 hours;

ab. 1 week;

ac. 2 weeks;

ad. 3 weeks. 